\title{
Late Glacial trees
}

\section{A group of botanists, geographers and physicists foraged through gravel pits, tunnel plots and lignite mines for very rare logs from the Late Glacial.}

\begin{abstract}
What was the objective of the work at the beginning of the project?

The Late Glacial period was a time of pronounced climate fluctuations and is therefore an extremely interesting period for the study of climate change. Through 35 years of continuous work on tree rings of subfossil oaks and pines, we built up the longest unbroken tree-ring record in the world, which reaches 12,500 years back in time and just touches the Late Glacial period. One goal of our project was to establish tree-ring chronologies in the Late Glacial period and connect them to the existing absolute chronology to provide a true annual timescale for accurate radiocarbon calibration and tree-ring proxies for climate reconstructions.
\end{abstract}

\section{Why did you choose those particular locations for the fieldwork?} During the Late Glacial period, trees were very sparse in Central Europe, and they are preserved for thousands of years only in special conditions. So it takes experience and good fortune to find ancient trees preserved in sediments or bogs. The mining industry is most helpful in uncovering old trees: open lignite pits, gravel pits or construction sites are the best places to look for ancient logs. At the site in Reichwalde, eastern Germany an archaeologist found the first logs in a bog beside a Palaeolithic campsite while surveying an open lignite pit. He informed us because he was interested in a tree-ring date of his Palaeolithic camp. Extensive excavations over the following seven years resulted in no more Palaeolithic finds, but we unearthed more than 2,000 trees from the Late Glacial period.

\section{What sorts of data or samples were}

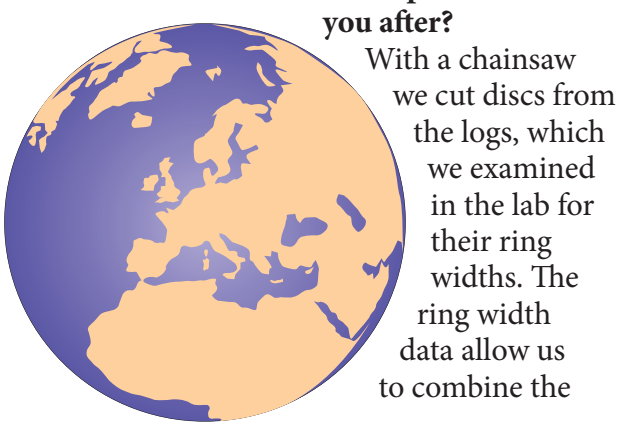

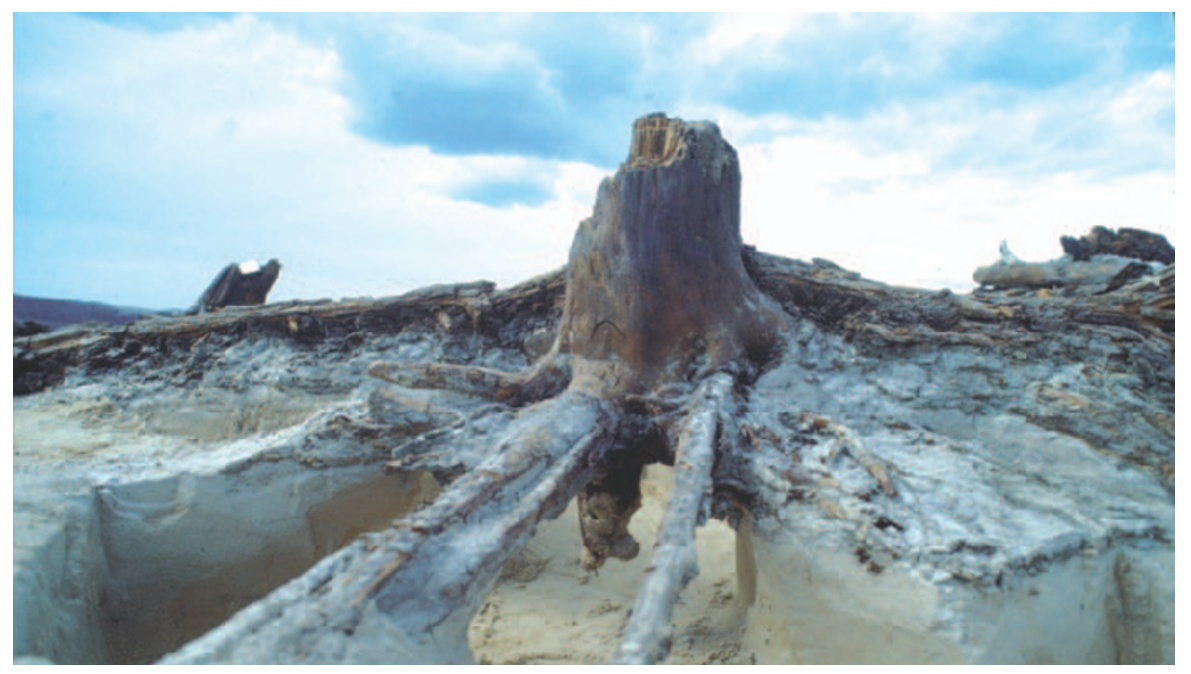

A pine stump from the Late Glacial period (13,400 yr BP) at the site in Reichwalde, eastern Germany.

various trees by their ring pattern into a single consistent tree-ring chronology, which is, however, 'floating' rather having an absolute date. The chronologies can be tentatively fixed in time by radiocarbon measurements. Once a chronology is established we perform high-precision radiocarbon measurements on series of well defined tree-rings, which can then serve as a radiocarbon calibration dataset.

What was the highlight of the expedition? One highlight of our fieldtrips was finding 36 huge pine logs in a gravel pit near Turin in the Po valley of northern Italy at the eleventh hour of a long field trip. After visiting dozens of gravel pits throughout the week with no finds of Late Glacial wood, we entered this one on a Friday afternoon at $3 \mathrm{pm}$, without much hope of finding any as we had regularly visited the pit for years. This time, however, there was a huge pile of subfossil pine trunks, clearly of old age, but the head of the company told us that the pit would close one hour later. The following hour was an exceptional chainsaw massacre. We left the site - in time - exhausted, but with samples of the 36 pines, which turned out to be the oldest we had ever found. That was perhaps the luckiest day we had during the project.
Did you learn anything new about yourself or of your team members? Joining a small group of acquainted botanists, physicists, geographers and geologists and driving for weeks in the same car, from one gravel pit to the next, with no air conditioning and sharing discussions over dinner every evening is the best palaeoclimate training you can get. We all profited greatly from working together in the ESF-EuroClimate project.

Did the trip give you any ideas for future research projects?

Within the project we have made a big step toward a continuous tree-ring chronology 14,500 years back in time. And we discovered samples and sites with radiocarbon dates back to 35,000 years BP. So we might be able to extend European dendrochronology into Glacial time - even if it takes an enormous effort and long continuous field work in southern Europe.

Michael Friedrich wrote this Backstory to the work by Muscheler and colleagues, published on page 263 of this issue. 